\title{
Benjamin Dahlke
}

\section{Die katholische Rezeption Karl Barths}

\author{
Theologische Erneuerung im Vorfeld des Zweiten Vatikanischen Konzils
}

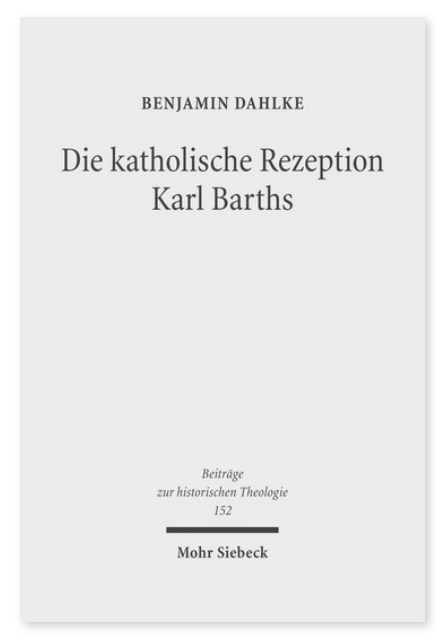

2010. IX, 257 Seiten. BHTh 152

ISBN 978-3-16-151062-5

DOI 10.1628/978-3-16-151062-5

eBook PDF 104,00€

ISBN 978-3-16-150382-5

Leinen $104,00 €$
Das Denken Karl Barths ist nicht nur auf evangelischer Seite auf reges Interesse gestoßen, auch katholische Theologen haben sich intensiv mit ihm auseinandergesetzt. Wie dies geschah und warum, zeichnet Benjamin Dahlke in dieser Studie für die Zeit vor dem Zweiten Vatikanischen Konzil nach. Er zeigt, dass die Beschäftigung mit dem »Römerbrief« und der »Kirchlichen Dogmatik« ein Anstoß zur theologischen Erneuerung war, also im Kontext der allmählichen Auf- und Ablösung der Neuscholastik zu verstehen ist. Thematisiert werden beispielsweise Hans Urs von Balthasars kritische Aneignung von Barths Denken und die mit Erich Przywara verknüpfte Debatte um die analogia entis. Damit soll ferner ein Beitrag zur Biographie Karl Barths geleistet werden. Barth unterhielt nämlich vielfältige, teils sogar freundschaftliche Kontakte zu Katholiken, die für die Genese seines Denkens wichtig sind.

Für dieses Werk erhielt Benjamin Dahlke den von der Akademie der Wissenschaften zu Göttingen verliehenen Hanns-LiljePreis 2010 .

Benjamin Dahlke Geboren 1982; Studium der Philosophie und Theologie in Paderborn, München, Princeton und Mainz; seit 2007 Assistent an der Katholisch-Theologischen Fakultät der Universität Mainz; 2009 Promotion, 2010 Hanns-Lilje-Preis für "Die katholische Rezeption Karl Barths".

Jetzt bestellen:

https://mohrsiebeck.com/buch/die-katholische-rezeption-karl-barths-9783161510625?no_cache=1

order@mohrsiebeck.com

Telefon: $+49(0) 7071-923-17$

Telefax: $+49(0) 7071-51104$ 